\title{
Outdoor Music Festivals: Cacophonous consumption or melodious moderation?
}

\section{Authors:}

Ms. Theresa Martinus

National Substance Use Liaison Officer (Alcohol)

Scottish Association of Alcohol and Drug Action Teams

166 Buchanan Street

Glasgow

G1 2LW

Dr. John McAlaney

Lecturer in Psychology and Research Methods

Centre for Psychology Studies

University of Bradford

Bradford,

BD7 1DP,

Mr. Liam J. McLaughlin

Alcohol and Drug Policy Officer

Perth and Kinross Council

Council Buildings

2 High Street

Perth

$\mathrm{PH} 15 \mathrm{PH}$

Ms. Hilary Smith

Alcohol and Drug Policy Officer

West Lothian Council

West Lothian House

Almondvale Boulevard

Livingston

EH54 6QG

Address for correspondence: Theresa Martinus, SAADAT, 166 Buchanan St., Glasgow, G1 2LW, Telephone: 0141572 6283, email: theresa.martinus@saadat.org.uk 


\title{
Outdoor Music Festivals: Cacophonous consumption or melodious
}

\author{
moderation?
}

\begin{abstract}
Large outdoor music festivals have emerged as part of a general expansion of licensed recreational activities but in research terms have been largely impenetrable due to commercial sensitivities. These sensitivities notwithstanding, the number and scale of such events necessitates a greater understanding of alcohol and drug use and the potential to promote normative protective behaviours in this context. This study examines self-reported alcohol and drug behaviours of 1,589 attendees at a music festival in Scotland during the summer of 2008. Similarities between outdoor rock music festivals and the dance club scene are considered alongside the challenges associated with risk reduction in these settings. Results show that alcohol was consumed by the majority of the sample; however, negative consequences were reported by a minority of respondents, suggesting evidence of controlled hedonism within a situation traditionally associated with unrestrained excess. Similarly the majority of the sample did not use drugs. The majority also report a number of selfregulating protective behaviours suggesting alcohol and drug use is contained within a developing social culture of "controlled intoxication". Results further suggest that although music festivals are transitory events there is a degree of consistency amongst attendees. Music festivals may therefore be atypical but potentially effective environments in which to increase protective behaviours using normative messaging and modern communications media. This study was resourced exclusively by local alcohol and drug partnerships.
\end{abstract}

Key words: Alcohol, Drugs, Outdoor Music Festivals, Protective Normative Behaviour

Word Count $-3,014$ 


\section{Outdoor Music Festivals: Cacophonous consumption or melodious moderation?}

\section{INTRODUCTION}

Concern has been expressed throughout Europe about the increasing risk of alcohol (and drug) related harm to music festival attendees (EMCDDA, 2006). Research studies at music festivals are relatively rare not least because of the powerful commercial interests involved and their reluctance to support research that might attract negative publicity. As a result, most UK studies have tended to focus on the dance club scene and it is to this body of literature that the authors of this study looked first.

Music festivals and 'clubbing' venues and attendees have much in common, for example, the creation of a festival atmosphere, loud popular music, the search for temporary freedom from the restraints imposed by work or study and, according to some authors such as Measham (2006) evidence of a single-minded determination by attendees to get drunk.

Differences also exist in that the late 1990s dance club scene is associated with weekend recreational consumption of club drugs such as ecstasy, LSD, amphetamine and cannabis. Alcohol was not a prominent feature of the clubbing scene at that time. This situation has now changed and alcohol's status in the music and dance scene has been re-established. The EMCDDA (2006) reports evidence that alcohol producers and manufacturers are now 
beginning to capitalise on this potentially lucrative music market, targeting new drinks at younger age groups, especially young women. This report raises important concerns about the health risks of festival attendees and the risk of excessive drinking, which may be combined with illegal drugs. Other researchers express similar concerns with the introduction, by some alcohol producers, of flavoured alcoholic drinks and ready-to-drink mixers; aspirational advertising campaigns and; the remodelling and growth of licensed recreational sites to appeal to a broader range of customers (Parker et. al. 1998; Duff, 2005; and Measham 2006).

In general terms, the dance and music scene has tended to be characterised by an ethos of premeditated intoxication and a growth in licensed entertainment (Measham, 2006). Large outdoor music festivals have emerged as part of this general expansion but in research terms have been largely impenetrable. Commercial sensitivities notwithstanding, the number and scale of these events necessitates a greater understanding of alcohol and drug behaviours in this context and the potential for risk reduction. A web-search using the works "UK rock festivals” provided twenty-five licensed and heavily promoted events across the UK (Table 1). Among the unique aspects of this type of event are their duration, two-five days, and the tens of thousands of people using temporary camp-site facilities. This raises a number of public health concerns as well as the question of the efficacy of risk reduction efforts in this context.

Table 1- Here 
The overall wisdom of investing limited resources to influence powerful commercial interests which may only exist in an area for a short period of time has been questioned (Mistral et al. 2007). This report by UKCAPP (2007) compares partnership risk reduction activity and community action programmes to "a barricade of small sandbags attempting to hold back the effects of a huge rising flood of alcohol consumption”. Other researchers express similar views (Berridge et al. 2008). In contrast, the EMCDDA (2006) encourages a degree of optimism particularly in regard to demand reduction among attendees. The authors speculate that "For the majority of people, particularly young people, across the EU, drink and drug use are still not necessarily an integral element of dance music settings. For most people it is the music and social aspects that are the most central experiences in this environment”.

Several studies emphasise the importance of setting and are worth mentioning here. Loud music and a 'clubbing' environment were associated with increased use of both alcohol and drugs and a need for more information among 18-30 year olds (The Health Promotion Agency, Ireland 2006). Bellis and colleagues (2002) demonstrated that music and dancing events were associated with the highest levels of consumption. Similar findings were demonstrated in research focusing on Edinburgh night clubs and pubs (Riley et al. 2001). A key finding in this study is the dominance of alcohol in the dance scene. Again, authors point to the shift from previous studies in which dance drug users were thought to avoid alcohol and raise concerns about the use of alcohol in conjunction with other drugs.

There is general agreement in the literature that both alcohol and drugs now dominate the increasing range of licensed recreational activity across the UK (Measham 2004). The harm associated with this type of activity is also well researched and accepted (Riley et. al. 200, 
EMCDDA). There is less agreement on what can be achieved by attempting any type of intervention when personal, group, commercial and environmental factors combine to create a context geared to unrestrained overindulgence.

Risk reduction efforts in the 'club scene' have benefited from two U.K. Government publications the "national safer clubbing guidelines on good practice” (Webster, Goodman \& Whalley, 2002); and “Good Practice in Managing the Evening and Late Night Economy”, Office of Deputy Prime Minister (2004). No good practice guidelines have been produced for music festivals where efforts are still largely progressed locally, by alcohol and drug partnerships (ADPs), giving rise to a variety of local responses. The purpose of this study is to further our understanding of drug and alcohol use and protective normative behaviours in the context of large scale outdoor music festivals.

\section{METHODS}

\section{Participants}

The population of interest are individuals attending licensed music festivals in Scotland. Festival attendees come from all parts of Scotland; therefore, the results of this work are thought to be of interest to Scotland as a whole. A total of 1,589 festival attendees voluntarily took part in an anonymous survey. 
Measures

After reviewing the literature on this topic, a questionnaire was designed based on studies of licensed dance events in the UK and identified gaps in the existing literature. Questions included:

- demographics data: age and gender

- frequency of attending music festivals

- alcohol and drug use

- when alcohol was purchased i.e. before or at the event.

- getting home from the festival.

- negative consequences of alcohol or drug consumption

- protective normative behaviours

No quantity questions were included in the survey because, under these conditions, self reported quantity measures are known to be of limited value (Midanik, 1989, Brener, Billy, and Grady, 2003).

\section{Procedure}

\section{Data collection}

Data collection was undertaken by twelve trained volunteer interviewers at the music festival site. Volunteers were supported and supervised by professional staff who distributed manageable numbers of questionnaires, ten, to each interviewer. Upon completion of the 
allocated forms, interviewers returned to the alcohol and drug partnership area for a well earned rest and debrief. Professional staff retained completed forms in a safe area during the festival.

\section{RESULTS}

In all cases, where Chi-squares tests were carried out results are based on the raw scores and not the percentages. However, although chi square results produce a statistically significant relationship this does not necessarily mean that it is of any real importance. To determine the importance of the relationship the value of the Cramer's $V$ test is also considered here. Anything below a value of 0.2 is considered relatively unimportant.

\section{Characteristics of the sample}

A total of 1,589 respondents completed the survey at the event. This consisted of 715 male respondents (45\%) and 874 female respondents (55\%), with a mean age of 23 years and a standard deviation of 7.3 years. The majority of the respondents (68\%) had attended this festival previously, whereas the remainder were attending for the first time. The majority of the sample (77\%) also reported attending between one and two music festivals a year, suggesting that although music festivals are transitory events there is a degree of consistency amongst attendees.

\section{Geographical breakdown}

Survey respondents provided the following information about their home location. There was no statistical difference between geographical area on any drug use or alcohol use. 
Table 2 - Here

\section{Alcohol Use}

The majority of participants ( $n=1398$ i.e. 88\%) reported drinking alcohol when attending the festival, with males significantly more likely to do so than females $\left(X^{2}=27.4, \mathrm{df}=1, \mathrm{p}<\right.$ 0.001). The likelihood of attendees drinking alcohol was also found to increase with age (rpb $=0.073, \mathrm{p}<0.05)$.

The most popular alcoholic beverage consumed by attendees was beer (consumed by 58\% of those who drank alcohol), followed by spirits (48\%), cider (45\%), wine (29\%), a mixture of drinks (25\%) and alcopops (20\%). It was noted that males were significantly more likely to report drinking beer $\left(\mathrm{X}^{2}=2.5, \mathrm{df}=1, \mathrm{p}<0.01\right)$, whereas females were significantly more likely to report drinking wine $\left(\mathrm{X}^{2}=8.4, \mathrm{df}=1, \mathrm{p}<0.01\right)$.

Most respondents brought alcohol to the event and topped-up by purchasing more during the event itself. A total of $78 \%$ of respondents who drank alcohol reported bringing alcohol with them to the event, whereas $72 \%$ also reported buying alcohol at the event. Older adults (25 years and above) were found to be significantly more likely to bring alcohol with them (rpb = 0.132, $\mathrm{p}<0.001)$ whereas young adults (16-24 years) were significantly more likely to buy alcohol at the event $(\mathrm{rpb}=-0.124, \mathrm{p}<0.001)$. A minority $(24 \%)$ stated that they obtained alcohol from their friends at the festival, with males being significantly more likely to do so than females $\left(\mathrm{X}^{2}=39.67, \mathrm{df}=1, \mathrm{p}<0.001\right)$, as were older adults compared to younger adults $(\mathrm{rpb}=0.204, \mathrm{p}<0.001)$. However, the strength of all age effects on both the source of 
alcohol and choice of alcoholic beverage were relatively weak, suggesting that age is not a major factor in determining these alcohol behaviours.

\section{Illegal Drug Use}

In contrast to alcohol use the majority of respondents (68\%) did not report any type of drug use whilst attending the festival. It should be noted, however, that those individual who used one drug also tended to use other drugs. The most commonly reported drug was cannabis, used by $24 \%$ of the sample. This was followed by ecstasy (16\%), cocaine (13\%), amphetamines (8\%), LSD (6\%) or other (4\%). Only 2\% of the sample reported using the bogus drug semeron, suggesting that individuals were not simply reporting using every drug. Individuals who reported using this bogus drug were excluded from the analysis. These findings are consistent with those reported by other researchers (Neighbors et. al. 2007), where alcohol was the most prevalent substance, the second most prevalent being cannabis, followed by stimulants.

\section{Age and 'any' illegal drug use}

Table 3 below illustrates that attendees in the age groups under 18 and over 35 were least likely to use illegal drugs. The 18 to 24 year group were most likely to do so.

Table 3 - Here 


\section{Gender}

There were marked gender differences in reporting drug use. Males were almost twice as likely to do so (41\%) compared to females (22\%). $\quad\left(\chi^{2}=62.68, \mathrm{df}=1, \mathrm{p}<0.001\right.$; Cramer's V $=0.20$ ). A value of 0.20 on this test indicates the finding to be rather trivial. Table 4 list the results for specific substances.

Table 4 - Here

A greater proportion of males also reported experiencing negative consequences as a result of using alcohol or drugs at festivals. Males were more likely to report collapse (6\% vs $2 \%$ ); more likely to be affected by heatstroke (13\% vs $8 \%$ ); more likely to vomit (14\% vs $8 \%$ ); more likely to be involved in a fight (9\% vs 3\%); and, more likely to report unsafe sex (10\% vs $3 \%)$.

\section{Getting Home}

The majority of respondents, $72 \%$, reported that they would not drive themselves home after the festival. The study did not consider driving under the influence and it is not known whether the $28 \%$ who intended to drive were affected in this way. 


\section{Negative experiences}

Negative experiences were in the minority. The two most common negative experiences reported by participants were vomiting (10.4\%) and heatstroke (10.2\%). A number of other experiences were reported by participants, which included engaging in unsafe sex (5.9\%), fighting (5.8\%), collapsing (3.8\%) or other consequences (3.3\%). Males were significantly more likely to experience collapse $\left(X^{2}=15.6, \mathrm{df}=1, \mathrm{p}<0.001\right)$, heatstroke $\left(X^{2}=7.9, \mathrm{df}=1\right.$, $\mathrm{p}<0.01)$, vomiting $\left(\mathrm{X}^{2}=17.8, \mathrm{df}=1, \mathrm{p}<0.001\right)$ and fighting $\left(\mathrm{X}^{2}=27.9\right.$, df $\left.=1, \mathrm{p}<0.001\right)$ compared to females.

\section{Protective behaviours}

It is important to stress the majority of protective behaviours evident in the sample. The majority brought sunscreen (51\%), brought water (72\%), ate whilst consuming alcohol (68\%), stayed in groups of friends (68\%) and kept mobile phone numbers (67\%).

Other protective behaviours were evident amongst the attendees, though by no means the majority. These included bringing condoms (23\%), pacing the consumption of alcohol (39\%) and avoiding mixing alcohol and drugs (28\%). Table 5, breaks down protective behaviours by gender. In terms of age, the under 18 age group were most likely to bring water and stick with friends (79\%). This age group were also most likely to keep safe mobile numbers (74\%). 
Table 5 Here

\section{DISCUSSION}

The point-biserials reported in this paper are statistically significant but likely to be so due to the large sample size. The actual size of the coefficients is small, as demonstrated by the Cramer V test results, and explains very little of the variance in age or gender differences.

This study used self-reported data, taking advantage of the relative ease and low cost with which they are gathered. Self-report data have become a popular way of measuring and describing the prevalence of many behaviours, including alcohol and illegal drug use in the general population. However, the validity of self-report data is sometimes called into question (e.g. Babor et al., 2000; Patrick et al., 1994; Frier et al., 1991; Midanik, 1988; Cooper et al., 1981). The data presented here are no better and no worse than other data of this type. Midanik (1989) acknowledged the variability in results obtained from using this type of methodology and suggests that the important issue is to understand the conditions in which self reports are likely to vary. In this survey, all efforts were made to ensure conditions were favourable e.g. The anonymity of respondents; the inclusion of a bogus drug 'semeron'; the information gathered was unlikely to be considered 'sensitive' by respondents in this context (Babor and Del Boca, 1992).

Despite the above limitations, results from the self-reported survey suggest several important points about the behavioural norms of festival attendees in general. Alcohol was consumed by the majority of the sample; however, negative consequences of drinking were only 
reported by the minority of respondents, supporting Measham (2006) findings that within an environment historically associated with unrestrained hedonism, behaviour is contained and intoxication is controlled. Similarly the majority of the sample did not use drugs, which is perhaps in contrast to the stereotypical image of a music festival attendee. Participants also engaged in a number protective behaviours including; $72 \%$ do not drive themselves home, the majority brought sunscreen and water, eat when drinking alcohol, stay with groups of their friends and keep safe mobile numbers.

It is possible that these behaviours could be used as the basis for a social norms approach (McAlaney and McMahon 2007; McMahon et al 2007) to risk reduction in this and similar settings. This technique is based upon disseminating healthy norm messages amongst a population, which - taking advantage of the fact that individuals are driven to match the norm - encourages that behaviour. For example, advertising the fact that most people who go to music festivals take bottled water would encourage those who have not previously done so to do so in future. This should reflect in numbers reporting 'dehydration' as a negative consequence. If this approach is taken then it would be necessary to take gender effects into account, for example it would be important to use norm messages which were targeted at both males and females. Given that the results demonstrate what appears to be a group of attendees who regularly come to the festival this effect could become cumulative from year to year. This approach of increasing rates of protective norms by praising the behaviour of the healthy majority has been used extensively in the American college system and appears to be a cost-effective method of reducing harm (Perkins et al 2005). Figure 1 (below) illustrates the logic of social norms interventions. 
Figure 1 - Here

A study by Measham and Brain (2005), explored the relationship between practices of selfregulation and social regulation and found that when drinkers discussed their desired and actual levels of intoxication in detail, they were bordered by concerns about health, personal safety and image. These factors were also found to interact with age and gender to produce a complicated set of influences on drinking practices resulting in controlled hedonism. These authors conclude that evidence is now beginning to emerge supporting the idea of a changing culture of intoxication. This emerging culture maintains some features of determined drunkenness as part of broader risk-taking, but this is thought to be restricted by what the authors refer to as being "bounded by occasion and location." It is within these contexts that risk reduction and demand reduction efforts could be developed.

Cacophonous consumption or melodies moderation? Results presented here suggest the answer lies somewhere in-between. Alcohol use at music festivals is the norm but negative consequences are uncommon. Drug use is minority behaviour. This reflects the shift previously noted by Riley (2001) and Measham (2004, 2006): alcohol is the drug of choice at clubbing venues and outdoor music festivals alike. Among the minority who use drugs, alcohol is no longer avoided, making poly-drug use a concern in this group. The impact of normative messages remains unknown in this context and requires further exploration. Findings presented elsewhere, however, suggest that sustained delivery of normative messages using new technologies could produce measurable reductions in problem behaviour 
and increases in protective behaviour. Recent work by Bewick et. al., (2008) highlights the potential of web-based normative messaging for this age group. 


\section{References}

Babor, T.F., Steinberg, K., Anton, R., and Del Boca, F. Talk is cheap: measuring drinking outcomes in clinical trials. Journal of Studies on Alcohol. 2000; 61(1):55-63.

Babor, T.F. and Del Boca, F.K. Just the facts: enhancing measurements of alcohol consumption using self-report methods. In: Litten, R. and Allen, J. (Eds.) Measuring Alcohol Consumption. Totawa, NJ: Humana Press, 1992.

Bellis, M.A., Hughes, K., Lowely, H. (2002). Healthy nightclubs and recreational substance use: from a harm minimisation use to a healthy setting approach. Addictive Behaviours. 27, 1025-1035.

Berridge, V., Thom, B., Herring, R. (2008). The normalization of binge drinking: an historical and cross cultural investigation with implications for action. AERC: Insight 49.

Bewick, B.M., Trusler, K., Mulhern, B., Barkham, M., Hill, A.J. (2008). The feasibility and effectiveness of a web-based personalised feedback and social norms alcohol intervention in UK university students: A randomised control trial. Addictive Behaviours. 33, 1192-1198.

Cooper, A.M., Sobell, M.B., Sobell, L.C., Maisto, S.A. Validity of alcoholics self-reports: duration data. International Journal of Addiction. 1981; 16: 401-406.

Duff, C. (2005). Party drugs and party people: Examining the 'normalisation' of recreational drug use in Melbourne, Australia. International Journal of Drug Policy, 16, 161-170.

European Monitoring Commission on Drugs and Drug Addiction (2006). Drug use in recreational settings. EMCDDA annual report, Chapter 4. http://annualreport.emcdda.europa.eu

Freier, M. C., Bell, Robert M., \& Ellickson, P. Do teens tell the truth? The validity of selfreported tobacco use by adolescents. Santa Monica, CA. The RAND Publication Series, 1991.

Health Promotion Agency Ireland (2006). Safer Clubbing Drugs Campaign. www.healthpromotionagency.org.uk/work/Drugs/publications.

McAlaney, J. \& McMahon, J. (2007) Normative beliefs, misperceptions and heavy episodic drinking in a British student sample. Journal of Studies on Alcohol and Drugs. Vol. 68, No. 3, 385 - 392.

McMahon, J., McAlaney, J., \& Edgar, F. (2007) Binge drinking behaviour, attitudes and beliefs in a UK community sample: an analysis by gender, age and deprivation. Drugs: Education, Prevention and Policy, Vol. 14, No. 4, 289 - 303. 
Measham, F. (2004). Play space: Historical and socio-cultural reflections on drugs, licensed leisure locations, commercialisation and control. International Journal of Drug Policy, 15, 337-345.

Measham, F. (2006). The New Policy Mix: alcohol, harm minimisation and determined drunkenness in contemporary society. The International Journal of Drug Policy. 17: 258268.

Measham, F., and Brain, K. (2005). 'Binge' drinking, British alcohol policy and the new culture of intoxication. Crime, Media, Culture: An International Journal, 1, 262-283.

Midanik, L. (1988). Validity of self-report alcohol use: a literature review and assessment. British Journal of Addictions. 1988; 83: 1019-1030

Midanik, L. (1989). Perspectives on the validity of self-report alcohol use. British Journal of Addictions. 1989; 84:1419-1423.

Mistral, D., Velleman, R., Mastache, C., Templeton, L. (2007). An evaluation of 3 UK Community Alcohol Prevention Programmes. UKCAPP: Mental Health R \&D Unit

Neighbors, et al (2007). Event-Specific Prevention: addressing college student drinking during known window of risk. Addictive Behaviours 32(2007) 2667 - 2680.

Office of the Deputy Prime Minister (2004). Good Practice in Managing the Evening and Late Night Economy. From http://www.communities.gov.uk/documents/communities/ pdf/131197.pdf

Parker, H., Aldridge, J. \& Measham, F. (1998). Illegal leisure: The normalization of adolescent recreational drug use. London: Routledge.

Perkins, H.W., Haines, M.P., Rice, R. (2005). Misperceiving the college drinking norm and related problems: a nationwide study of exposure to prevention information, perceived norms and student alcohol misuse. Journal of Studies on Alcohol, Jul;66(4):470-8

Riley, S.C.E., James, C., Gregory, D., Dingle, H., Cadger M. (2001). Patterns of recreational drug use at dance events in Edinburgh, Scotland. Addiction, 96, 7, 10351047.

Webster, R., Goodman, M, \& Whalley, G. (2002). Safer clubbing: Guidance for licensing authorities, club managers and promoters. London. Drugs Prevention Advisory Service. 
Table 1 - UK Multi-Day Rock Festivals in 2009

\begin{tabular}{|c|c|c|c|}
\hline Name & Location and & Duration & 2009 Dates \\
\hline Glastonbudget & Leicestershire, & 3 days & May \\
\hline Wychwood & Cheltenham, & 3 days & May \\
\hline Isle of White Festival & Isle of White, & 3 days & June \\
\hline Download Festival & Leicester & & June \\
\hline Rock Fest & Loch Ness, Scotland, & 3 days & June \\
\hline Glastonbury & Somerset, & 5 days & June \\
\hline Hyde Park Calling & London, & & dates to be confirmed \\
\hline Guilfest & Surrey, & 3 days & July \\
\hline T in the Park & Kinross, Scotland, & 3 days & July \\
\hline Oxegen & Ireland & 3 days & July \\
\hline Latitude & Suffolk & 4 days & July \\
\hline Secret Garden Party & Cambridgeshire & 4 days & July \\
\hline Truck Festival & Oxfordshire & 2 days & July \\
\hline $\begin{array}{l}\text { Rock and Blues cancelled - council } \\
\text { denied licence application }\end{array}$ & Derbyshire & 4 days & July 24 \\
\hline Gig in the Park & Suffolk & 3 days & August. \\
\hline Bloom Festival & Cheltenham & & Dates to be confirmed \\
\hline Beautiful Days & Devon & 3 days & August \\
\hline Green Man & Wales & 3 days & August \\
\hline 'V’Festival & Essex & 2 days & August \\
\hline 'V' Festival & Staffordshire & 2 days & August \\
\hline Leeds & Leeds & 3 days & August \\
\hline Reading & Reading & 3 days & August \\
\hline Last Days of Summer & Northampton & & August dates to be confirmed. \\
\hline County Picnic & Co Laosis, Ireland & 3 days & September \\
\hline Loopallu Fest & Ullapool, Scotland & 2 days & September \\
\hline Guitarfest & Birmingham & & September dates to be confirmed \\
\hline
\end{tabular}


Table 2 - Home post code area of attendees

\begin{tabular}{|l|l|l|}
\hline Post Code Area & Percentage & Number \\
\hline Edinburgh & 19 & 301 \\
\hline Glasgow & 17 & 270 \\
\hline Kirkcaldy & 15 & 238 \\
\hline Dundee & 10 & 159 \\
\hline Aberdeen & 8 & 127 \\
\hline Falkirk & 6 & 95 \\
\hline Perth & 5 & 80 \\
\hline Paisley & 4 & 64 \\
\hline Motherwell & 3 & 48 \\
\hline Inverness & 2 & 32 \\
\hline Kilmarnock & 2 & 32 \\
\hline Dumfries & 1 & 16 \\
\hline Galasheils & 1 & 111 \\
\hline Outside Scotland & 7 & \\
\hline Percentages have been & & \\
\hline
\end{tabular}

Percentages have been rounded to the nearest whole number

Table 3 - age and illegal drug use at festivals.

\begin{tabular}{|l|l|l|}
\hline Age & Percentage & Number \\
\hline$<18$ & $20 \%$ & 318 \\
\hline $18-24$ & $32 \%$ & 509 \\
\hline $25-35$ & $28 \%$ & 445 \\
\hline $35+$ & $17 \%$ & 270 \\
\hline Missing data & $3 \%$ & 47 \\
\hline
\end{tabular}

Percentages have been rounded to the nearest whole number 
Table 4 - Gender and specific drug use.

\begin{tabular}{|l|l|l|l|l|l|l|l|}
\hline Drug & $\begin{array}{l}\text { Total } \\
\%\end{array}$ & Number & $\begin{array}{l}\text { Male } \\
\%\end{array}$ & $\begin{array}{l}\text { Male } \\
\text { Number }\end{array}$ & $\begin{array}{l}\text { Female } \\
\%\end{array}$ & $\begin{array}{l}\text { Female } \\
\text { Number }\end{array}$ & $\begin{array}{l}\text { Statistical Significance } \\
.\end{array}$ \\
\hline Cannabis & 24 & 386 & 32 & 232 & 17 & 154 & $\begin{array}{l}\left(\chi^{2}=58.03, \mathrm{df}=1, p<0.001 ;\right. \\
\text { Cramer's V }=0.19)\end{array}$ \\
\hline Ecstasy & 16 & 256 & 22 & 160 & 11 & 96 & $\begin{array}{l}\left(\chi^{2}=57.2, \mathrm{df}=1, p<0.001 ;\right. \\
\text { Cramer's V =0.19); }\end{array}$ \\
\hline Cocaine & 13 & 203 & 17 & 129 & 9 & 74 & $\begin{array}{l}\left(\chi^{2}=42.28, \mathrm{df}=1, p<0.001 ;\right. \\
\text { Cramer's V }=0.17) .\end{array}$ \\
\hline Amphetamine & 8 & 131 & 10 & 71 & 6 & 60 & $\begin{array}{l}\left(\chi^{2}=14.82, \mathrm{df}=1, p<0.001 ;\right. \\
\text { Cramer's V }=0.11) ;\end{array}$ \\
\hline LSD & 6 & 91 & 8 & 57 & 4 & 34 & $\begin{array}{l}\left(\chi^{2}=21.17, \mathrm{df}=1, p<0.001 ;\right. \\
\text { Cramer's V }=0.12)\end{array}$ \\
\hline Other & 4 & 62 & 6 & 43 & 2 & 19 & $\begin{array}{l}\left(\chi^{2}=6.54, \mathrm{df}=1, p<0.05 ;\right. \\
\text { Cramer's V }=0.07) .\end{array}$ \\
\hline
\end{tabular}

Festival goers who used one drug, tended to use others as well, hence the numbers in this table will not add up 100\%. Percentages have been rounded to the nearest whole number.

Table 5- Protective behaviours by gender

\begin{tabular}{|c|c|c|c|c|c|c|c|}
\hline $\begin{array}{l}\text { Protective } \\
\text { Behaviour }\end{array}$ & $\begin{array}{l}\text { Total } \\
\%\end{array}$ & Number & $\begin{array}{l}\text { Male } \\
\%\end{array}$ & $\begin{array}{l}\text { Male } \\
\text { Number }\end{array}$ & $\begin{array}{l}\text { Female } \\
\%\end{array}$ & $\begin{array}{l}\text { Female } \\
\text { Number }\end{array}$ & Statistical Significance \\
\hline Bring water & 72 & 1144 & 68 & 486 & 75 & 658 & $\begin{array}{l}\left(\chi^{2}=7.75, \mathrm{df}=1, p<0.001\right. \\
\text { Cramer's } V=0.07)\end{array}$ \\
\hline $\begin{array}{l}\text { Eat prior to } \\
\text { drinking } \\
\text { alcohol }\end{array}$ & 68 & 1081 & 65 & 465 & 71 & 616 & $\begin{array}{l}\left(\chi^{2}=42.28, \mathrm{df}=1, p<0.05 ;\right. \\
\text { Cramer's V = 0.06). }\end{array}$ \\
\hline $\begin{array}{l}\text { Stick with and } \\
\text { look out for } \\
\text { friends during } \\
\text { the festival. }\end{array}$ & 68 & 1081 & 59 & 422 & 75 & 659 & $\begin{array}{l}\left(\chi^{2}=51.26, \mathrm{df}=1, p<0.001\right. \\
\text { Cramer's V = 0.18). }\end{array}$ \\
\hline $\begin{array}{l}\text { Keep safe } \\
\text { mobile } \\
\text { phone } \\
\text { numbers }\end{array}$ & 66 & 1049 & 66 & 472 & 66 & 577 & $\mathrm{n} / \mathrm{s}$ for gender \\
\hline $\begin{array}{l}\text { Bring } \\
\text { sunscreen }\end{array}$ & 51 & 810 & 41 & 293 & 59 & 517 & $\begin{array}{l}\left(\chi^{2}=46.92, \mathrm{df}=1, p<0.001\right. \\
\text { Cramer's V = 0.17) }\end{array}$ \\
\hline $\begin{array}{l}\text { Pace alcohol } \\
\text { consumption } \\
\text { by alternating } \\
\text { alcoholic and } \\
\text { non alcohol } \\
\text { drinks }\end{array}$ & 29 & 461 & 26 & 186 & 32 & 275 & $\begin{array}{l}\left(\chi^{2}=7.90, \mathrm{df}=1, p<0.001\right. \\
\text { Cramer's V = 0.07). }\end{array}$ \\
\hline $\begin{array}{l}\text { Avoid mixing } \\
\text { alcohol and } \\
\text { drugs }\end{array}$ & 28 & 445 & 26 & 186 & 29 & 259 & $\mathrm{n} / \mathrm{s}$ for gender \\
\hline $\begin{array}{l}\text { Bring } \\
\text { Condoms }\end{array}$ & 23 & 365 & 35 & 250 & 13 & 115 & $\begin{array}{l}\left(\chi^{2}=107.82, \mathrm{df}=1, p<0.001 ;\right. \\
\text { Cramer's V = 0.26). }\end{array}$ \\
\hline
\end{tabular}

Percentages have been rounded to the nearest whole number. 
Figure 1, The logic of normative interventions

\section{The logic of normative interventions}

Underlying problem

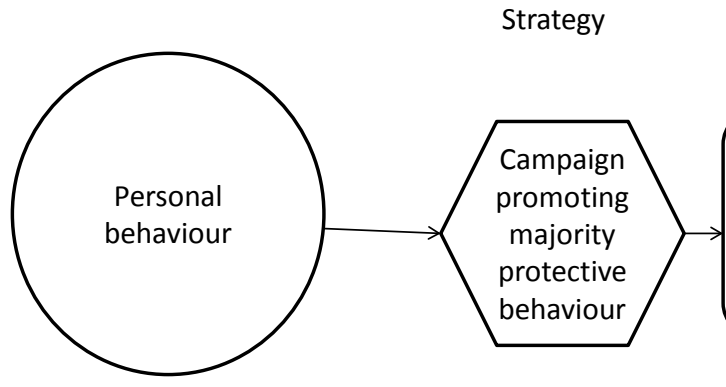

Anticipated outcome

Impact

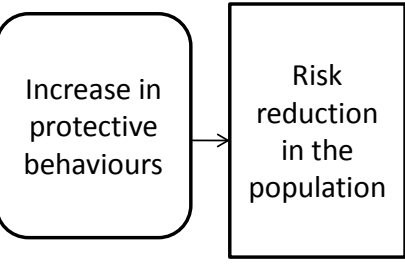

Evidence Needed

$$
\begin{aligned}
& \text { Prevalence of } \\
& \text { protective } \\
& \text { behaviours }
\end{aligned}
$$

Campaign
reached
intended
audience

$$
\begin{aligned}
& \text { Increase in } \\
& \text { protective } \\
& \text { behaviours }
\end{aligned}
$$

